\title{
ARTICLE \\ PKC activation sensitizes basal-like breast cancer cell lines to Smac mimetics
}

\author{
L Cornmark $^{1}$, C Holmgren ${ }^{1}, \mathrm{~K}$ Masoumi ${ }^{1}$ and C Larsson ${ }^{1}$
}

There is a need for novel strategies to initiate cancer cell death. One approach is the use of Smac mimetics, which antagonize inhibitor of apoptosis proteins (IAPs). Recent studies have shown that combinations of Smac mimetics such as LBW242 or LCL161 in combination with chemotherapeutic agents increase cancer cell death. Here we show that the protein kinase C (PKC) activator TPA together with the Smac mimetic LBW242 induces cell death in two basal breast cancer cell lines (MDA-MB-468 and BT-549) that are resistant to Smac mimetic as single agent. Ten other LBW242-insensitive cancer cell lines were not influenced by the TPA+LBW242 combination. The TPA+LBW242 effect was suppressed by the PKC inhibitor GF109203X, indicating dependence on PKC enzymatic activity. The PKC effect was mediated via increased synthesis and release of TNFa, which can induce death in the presence of Smac mimetics. The cell death, coinciding with caspase-3 cleavage, was suppressed by caspase inhibition and preceded by the association of RIP1 with caspase-8, as seen in complex II formation. Smac mimetics, but not TPA, induced the non-canonical NF- $k B$ pathway in both MDA-MB-231 and MDA-MB-468 cells. Blocking the canonical NF- $K B$ pathway suppressed TPA induction of TNF $a$ in MDA-MB-468 cells whereas isolated downregulation of either the canonical or non-canonical pathways did not abolish the Smac mimetic induction of the NF-KB driven genes TNFa and BIRC3 in MDA-MB-231 cells although the absolute levels were suppressed. A combined downregulation of the canonical and non-canonical pathways further suppressed TNFa levels and inhibited Smac mimetic-mediated cell death. Our data suggest that in certain basal breast cancer cell lines co-treatment of TPA with a Smac mimetic induces cell death highlighting the potential of using these pathways as molecular targets for basal-like breast cancers.

Cell Death Discovery (2016) 2, 16002; doi:10.1038/cddiscovery.2016.2; published online 29 February 2016

\section{INTRODUCTION}

Evasion of cell death is one important hallmark of cancer. ${ }^{1,2}$ Cell death comprises different subroutines ${ }^{3,4}$ with two main apoptotic pathways, the extrinsic and the intrinsic, as important examples. ${ }^{5}$ The extrinsic pathway is induced by death receptors (DRs) leading to the activation of caspase- 8 whereas the intrinsic apoptotic pathway is initiated by cellular stress resulting in release of cytochrome $c$ and second mitochondria-derived activator of caspase (Smac) from the mitochondria leading to activation of caspase-9. Both pathways converge in the activation of executioner caspases-3 and 7.6,7

One way to facilitate apoptosis induction and thereby circumvent the evasion of cell death by cancer cells is to mimic the function of Smac. Several small molecules mimicking Smac have been developed and some are under investigation in clinical trials. $^{8}$

A Smac mimetic (SM) is thought to facilitate cell death by mimicking the antagonizing effect of Smac on inhibitor of apoptosis proteins (IAPs). ${ }^{8}$ Two IAPs, cellular IAP1 (cIAP1) and CIAP2, regulate tumor necrosis factor receptor 1 (TNFR1) signaling. ${ }^{9}$ TNFR1 activation can lead to extrinsic apoptotic signaling pathway. However, TNFR1 also induces NF- $K B$ signaling associated with survival and inflammation. ${ }^{10}$ The effect of the TNFR1 signal is determined by proteins that are available and recruited to the receptor. ${ }^{11,12}$ After ligand binding, CIAP1 and CIAP2 are recruited to the receptor and induce ubiquitination of other proteins, including receptor-interacting protein-1 (RIP1).
Ubiquitination of RIP1 is necessary for the formation of complex $\mathrm{I}$, an essential step for induction of NF-KB signaling. SMs induce downregulation of ClAP1/2 thereby preventing complex I formation and NF-KB signaling. Instead complex II, is formed. Complex II contains FADD, RIP1 and caspase- 8 and leads to the activation of the latter and apoptosis. ${ }^{1,12}$ In addition, SM can facilitate cell death by blocking XIAP, a well-established caspase inhibitor. ${ }^{13}$

Some cancer cell lines die by SM treatment as single agent. ${ }^{14-17}$ The effect has been reported to be due to autocrine TNFa production, which induces cell death in the presence of SM. ${ }^{16,17}$ The TNF $a$ production can be mediated by accumulation of NF- $K B$ inducing kinase (NIK), followed by non-canonical NF- $K B$ signaling and TNFa transcription, which occur when clAPs no longer ubiquitinate and target NIK for degradation. ${ }^{17-19}$ However, it is not completely clear what determines if a cell responds to a SM with TNFa production. It also raises the possibility that local induction of TNFa may be a way to make cancer cells susceptible to SM.

We previously found that the pro-apoptotic protein Smac and the protein kinase $C$ (PKC) isoform PKC $\delta$ form a complex that is dissociated during cell death induction. ${ }^{20}$ Here we continue the investigation of Smac and PKC. We found that activation of PKC with subsequent synthesis and release of TNFa can overcome SM insensitivity in breast cancer cell lines of basal phenotype. The effect of TPA is dependent on the canonical NF- $\kappa$ B pathway, whereas both the canonical and non-canonical pathways contribute to sensitivity to SM.

\footnotetext{
${ }^{1}$ Department of Laboratory Medicine, Translational Cancer Research, Lund University, Lund, Sweden.

Correspondence: C Larsson (christer.larsson@med.lu.se)

Received 15 December 2015; accepted 16 December 2015; Edited by A Rufini
} 


\section{RESULTS}

PKC activation by TPA overcomes resistance to SM in MDA-MB-468 and BT-549 cells

To investigate a putative modulating effect of PKC on SM-induced death, we initially co-treated SM-sensitive MDA-MB-231 ${ }^{16,21}$ and MDA-MB-468 cells, which are insensitive to SM treatment (Figure 1a), with the PKC activator TPA and the SM LBW242. TPA made MDA-MB-468 cells sensitive to SM and increased the effect of SM on MDA-MB-231 cells (Figure 1a). Only one more of nine additional cell lines tested, the BT-549 breast cancer cell line, showed a similar response (Figure 1a), except for LNCaP cells, which die upon treatment of TPA alone. ${ }^{22}$ The effects on MDAMB-231 and MDA-MB-468 cells were the same with LCL161, which is another SM (Supplementary Figure 1). Because of limited availability of LBW242, LCL161 was used in some subsequent experiments.

We next evaluated the effects of TPA and SM together with the chemotherapeutic agents, etoposide and paclitaxel (Figure 1b). Both paclitaxel and etoposide alone suppressed cell viability and the effect was further enhanced by the addition of TPA and SM, indicating that the death-inducing effect can be even more pronounced with multiple agents. The TPA effect was blocked by the pan-PKC inhibitor GF109203X (Figure 1c), indicating that PKC activity is necessary for the effect.

Both MDA-MB-468 and BT-549 cells showed a significantly increased cell death, measured by an annexin $\mathrm{V}$ assay, upon

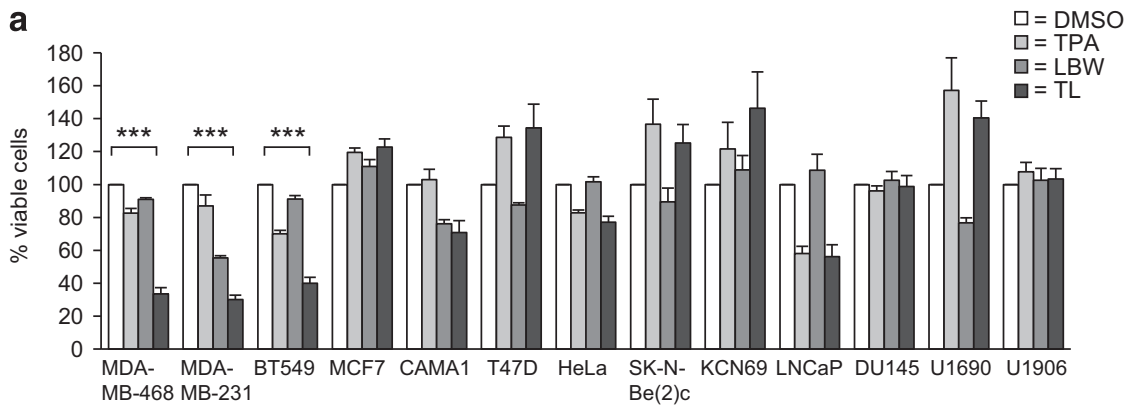

b

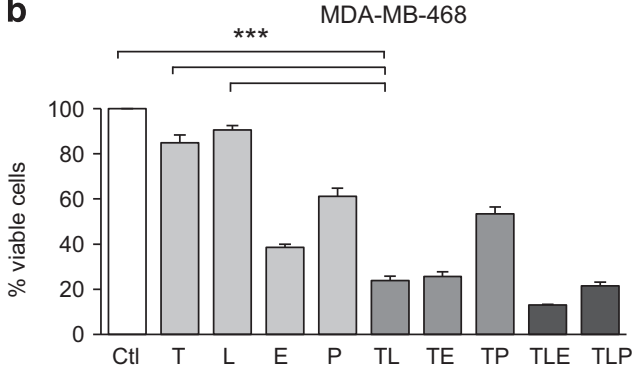

C

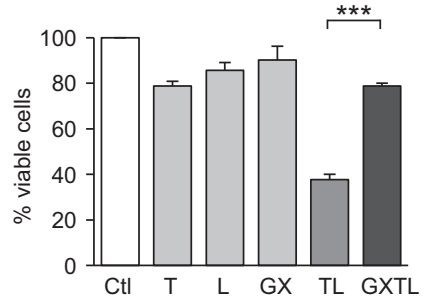

d
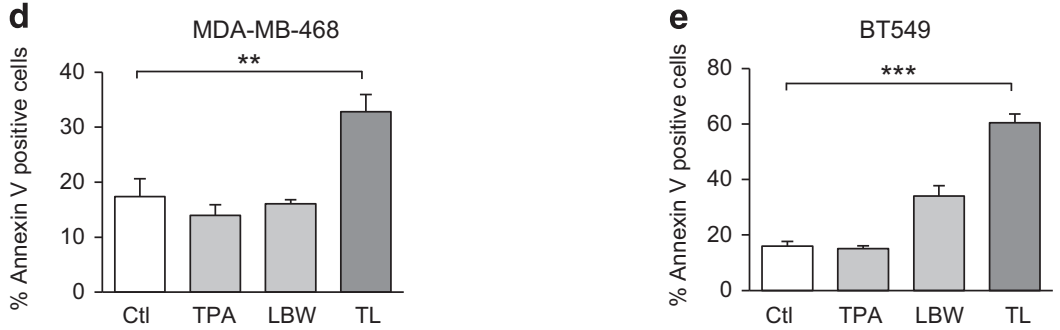

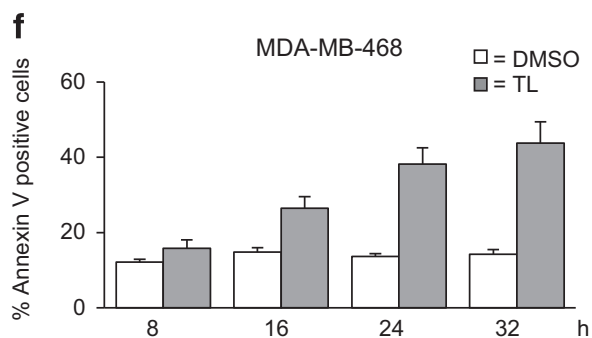

Figure 1. TPA overcomes resistance to LBW242 in MDA-MB-468 and BT-549 cells. (a) Different cancer cell lines were treated with 16 nM TPA, $20 \mu \mathrm{M}$ LBW242 or the combination of both (TL) for $30 \mathrm{~h}$. (b) MDA-MB-468 cells were treated for $30 \mathrm{~h}$ with indicated combinations of $16 \mathrm{nM}$ TPA (T), $20 \mu \mathrm{M}$ LBW242 (L), $100 \mu \mathrm{M}$ etoposide (E), $100 \mathrm{nM}$ paclitaxel (P) or with corresponding volume of DMSO (Ctl) as control. (c) MDA-MB-468 cells were treated for $30 \mathrm{~h}$ with indicated combinations of $16 \mathrm{nM}$ TPA, $20 \mu \mathrm{M}$ LBW242, $2 \mu \mathrm{M}$ GF109203X or with corresponding volume of DMSO as control. (d) MDA-MB-468 or (e) BT-549 cells were treated with $16 \mathrm{nM}$ TPA and/or $20 \mu \mathrm{M}$ LBW242 for $16 \mathrm{~h}$. (f) MDA-MB-468 cells were treated with $16 \mathrm{nM}$ TPA and $20 \mu \mathrm{M}$ LBW242 for 8, 16, 24 and $32 \mathrm{~h}$. Cell viability data in (a-c) were obtained with a WST-1 assay and are expressed as percentage of control cells. For (d-f) cell death was determined by flow cytometry using APC-conjugated annexin V. Data are mean \pm S.E.M. of $n \geq 3$ independent experiments; ${ }^{* *} P<0.01$ and ${ }^{* * *} P<0.001$. 


\section{a}

MDA-MB-468

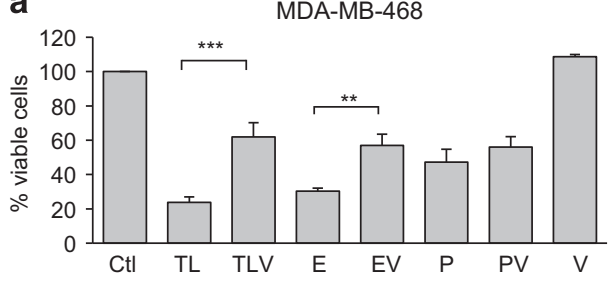

b

MDA-MB-468

C
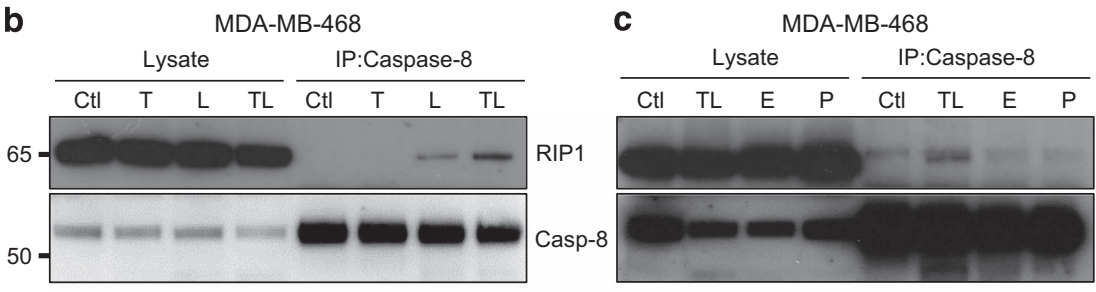

d

MDA-MB-468

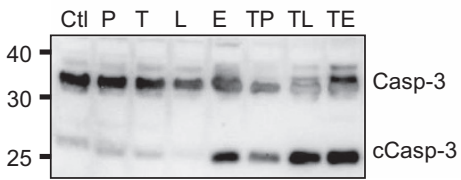

Figure 2. Combined treatment with TPA and LBW242 leads to caspase activation and complex II formation. (a) MDA-MB-468 cells were treated with indicated combinations of $16 \mathrm{nM}$ TPA (T), $20 \mu \mathrm{M}$ LBW242 (L), $100 \mu \mathrm{M}$ etoposide (E), $100 \mathrm{nM}$ paclitaxel (P) with or without $20 \mu \mathrm{M}$ of the pan-caspase inhibitor zVADfmk (V) or with corresponding volume of DMSO (Ctl) as control for $30 \mathrm{~h}$. Cell viability was determined with a WST-1 assay and is expressed as percentage values obtained for DMSO-treated control cells. (b) MDA-MB-468 cells were treated with 16 nM TPA and/or $20 \mu \mathrm{M}$ LBW242 or (c) $16 \mathrm{nM}$ TPA $+20 \mu \mathrm{M}$ LBW242 (TL), $100 \mu \mathrm{M}$ etoposide or $100 \mathrm{nM}$ paclitaxel for $16 \mathrm{~h}$. All treatments were done in the presence of $20 \mu \mathrm{M}$ zVADfmk. Cell lysates were immunoprecipitated with caspase-8 antibodies and analyzed with western blot, using antibodies against RIP1 and caspase-8. (d) MDA-MB-468 cells treated with indicated combinations of 16 nM TPA, $20 \mu \mathrm{M}$ LBW242, $100 \mu \mathrm{M}$ etoposide, $100 \mathrm{nM}$ paclitaxel or a DMSO control for $16 \mathrm{~h}$ were analyzed with western blot using antibodies against caspase-3. Data in (a) represent the mean \pm S.E.M. of $n \geq 3$ independent experiments; ${ }^{* *} P<0.01$ and ${ }^{* *} P<0.001$. Blots in (b-d) are representatives of three independent experiments.

treatment with the combination of TPA and SM (Figures $1 \mathrm{~d}$ and e). Thus, the decreased cell viability is increased conceivably due to cell death.

After $16 \mathrm{~h}$ of treatment, an increase in cell death can be observed (Figure 1f), which is further increased with time.

TPA in combination with SM induces complex II formation and caspase activation

Next, we sought to investigate mechanisms mediating cell death by TPA+SM. ${ }^{16,17}$ Caspase inhibition resulted in a marked reduction in cell death induced by TPA+SM and by etoposide but had limited effects on paclitaxel-mediated death (Figure 2a). It has been proposed that SM enables the formation of complex II upon TNFa stimulation with subsequent activation of caspase-8. ${ }^{16,17}$ To evaluate the formation of complex II, we used an approach previously described ${ }^{11,21}$ where caspase- 8 , one of the constituents of complex II, is immunoprecipitated. When treating cells with TPA alone caspase-8 did not co-immunoprecipitate with RIP1. However, SM treatment led to co-immunoprecipitation of RIP1 and caspase- 8 , which was further strengthened by simultaneous incubation with TPA (Figure 2b). Neither etoposide nor paclitaxel induced a caspase-8-RIP1 complex (Figure 2c).

The combination of TPA and SM also resulted in the cleavage of caspase-3 whereas neither TPA nor SM alone had this ability (Figure 2d). TPA together with paclitaxel or etoposide only showed a weak capacity to affect caspase-3.

TPA and SM-mediated cell death is TNFa dependent

Autocrine TNFa production has been reported to be important for SM-mediated cell death. ${ }^{16,17}$ We therefore examined if the cell death induced by TPA+SM is TNFa dependent as well. A TNFa- blocking antibody suppressed cell death induction both for MDAMB-468 cells treated with TPA and SM as well as for MDA-MB-231 cells treated with SM alone (Figures $3 a$ and b).

We next investigated whether TNF $a$ is sufficient to induce cell death in combination with SM in MDA-MB-468 cells. TNF $a$ alone had no effect but together with LBW242 a pronounced induction of cell death was seen (Figure 3c). For the SM-sensitive MDAMB-231 cells no potentiating effect of TNFa could be seen (Figure 3d).

TPA treatment leads to increased levels of TNFa

To investigate if TPA treatment results in TNFa production, we investigated TNFa levels in cell culture medium. TPA induced higher TNFa protein concentrations in the cell culture medium of MDA-MB-468 cells whereas SM had no effect, neither in the absence nor presence of TPA (Figure 4a). GF109203X abolished the effect of TPA. Contrasting MDA-MB-468 cells, SM alone resulted in increased TNFa levels in MDA-MB-231 cells (Figure 4a).

In MDA-MB-468 cells, TPA treatment also caused a modest (69\%) increase in TNFa mRNA levels and SM had no effect. On the other hand, TNFa mRNA levels in SM-treated MDA-MB-231 cells were markedly increased compared to basal levels (Figure 4b).

TPA led to a more than 19-fold elevation of TNFa protein concentration but only a $69 \%$ increase in TNFa mRNA levels in MDA-MB-468 cells. To analyze this discrepancy, the effect of TPA stimulation at different time points was investigated. TNFa protein levels gradually increased during the first 16 h (Figure 4c), whereas TNF $a$ mRNA levels preceded protein changes and peaked after $4 \mathrm{~h}$ of TPA treatment (Figure $4 \mathrm{~d}$ ). This conceivably explains the discrepancies between protein and mRNA levels after $16 \mathrm{~h}$ of treatment. 

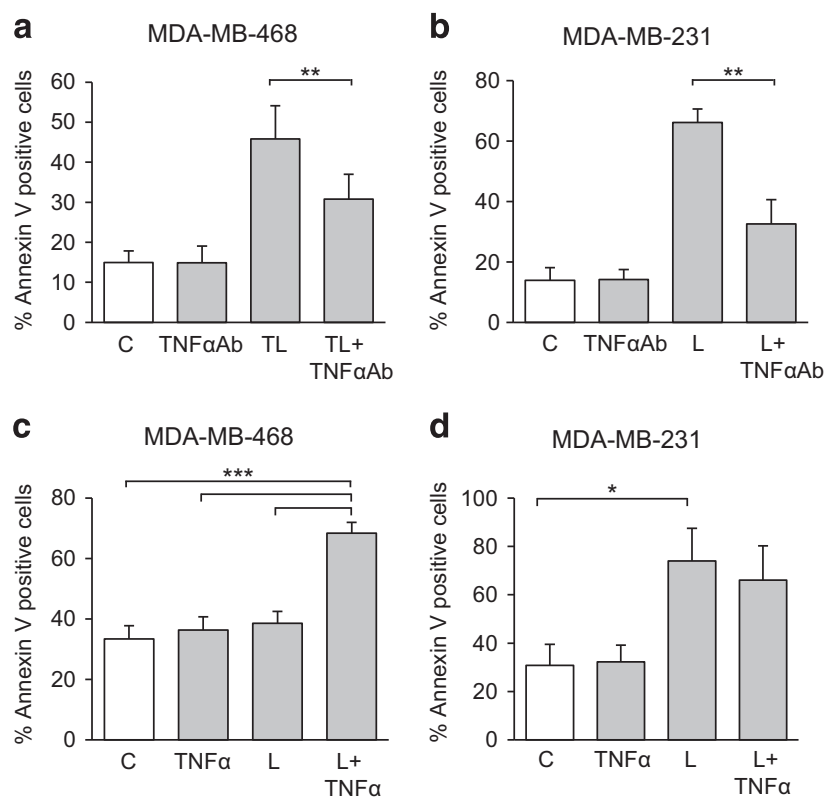

Figure 3. The cell death mediated by TPA and LBW242 is dependent on TNFa. Anti-human TNFa antibodies $(2 \mu \mathrm{g} / \mathrm{ml})$ were added to both (a) MDA-MB-468 cells treated with 16 nM TPA and $20 \mu$ M LBW242 as well as (b) MDA-MB-231 cells treated with $20 \mu \mathrm{M}$ LBW242 alone, for $16 \mathrm{~h}$. (c) MDA-MB-468 and (d) MDA-MB-231 cells were treated for $16 \mathrm{~h}$ with $20 \mu \mathrm{M}$ LBW242 and/or $2 \mathrm{ng} / \mathrm{ml}$ TNFa. Cell death was determined by flow cytometry using APC-conjugated annexin V. All data are mean \pm S.E.M. of $n \geq 3$ independent experiments; ${ }^{*} P<0.05$, ${ }^{* *} P<0.01$ and ${ }^{* * *} P<0.001$.

According to cell viability results (Figure 1a), most cell lines do not respond with decreased cell viability when combining a SM with TPA. This could potentially be due to an inability of TPA to induce TNF $a$ or a resistance to the combination of SM with TNFa. To assess these hypotheses, T47D and MCF-7 cells were treated with SM and TNFa followed by analysis of cell viability (Figure 4e). T47D cells were insensitive to this combination conceivably explaining the insensitivity to TPA and SM treatment. Although some cell death was induced in MCF-7 cells by the treatment the effect was not as pronounced as for MDA-MB-468 cells. Furthermore, TPA treatment of MCF-7 cells resulted in TNFa mRNA production but with lower and faster declining levels than in MDA-MB-468 cells (Figures $4 d$ and f). Thus, the insensitivity of MCF-7 cells to the combination of TPA and SM may depend on both a lower sensitivity to the combination of TNF $a$ and SM, and a smaller induction of TNFa by TPA.

Global gene expression of SM-treated sensitive and insensitive cell lines

To further delineate mechanisms mediating TNFa expression, we turned to comparison of the response to SM and analyzed changes in global gene expression following SM treatment of MDA-MB-231 and MDA-MB-468 cells. The most apparent finding was that SM-treated MDA-MB-231 cells had a substantially higher number of differentially expressed genes (108 genes) compared to the SM-treated MDA-MB-468 cells (nine genes), of which four were affected in both cell lines, when applying a $q$-value of $0 \%$ as a cutoff. All differentially expressed genes, except for OSR1 in MDAMB-231 cells were expressed at higher levels following SM treatment (Figures $5 \mathrm{a}$ and $\mathrm{b}$ ). Many of the SM-induced genes are NF- $K B$ target genes, such as BIRC3, CXCL1, IRAK2, TNF and TRAF $^{23}$ (Supplementary Table 1), which is further supported by a pathway analysis (Supplementary Figure 3).
Effects of SM on NF- $K B$ signaling in sensitive and insensitive cells To investigate why SM treatment leads to a more limited effect on gene expression in MDA-MB-468 than in MDA-MB-231 cells, molecular pathways known to be influenced by SM were analyzed. Exposure to SM resulted in an initial degradation of both cIAPs in MDA-MB-468 cells that was sustained for clAP1 but transient for CIAP2 (Figure 6a). The same pattern has been described in MDAMB-231 cells. ${ }^{21}$ Thus, this effect is similar in the two cell lines.

One possible outcome of CIAP1/2 degradation is the stabilization of NIK and subsequent processing of p100 to p52, which is indicative of non-canonical NF-KB signaling. SM treatment led to processing of p100 to $\mathrm{p} 52$ in both cell lines after $3 \mathrm{~h}$ (Figure $6 \mathrm{~b}$ ). TPA did not result in p100 processing in either cell line. Instead we found decreased levels of $I_{\kappa} \mathrm{B} a$ protein following TPA treatment (Figure $6 \mathrm{c}$ ), whereas SM had no effect here. This suggests that primarily the canonical NF- $\kappa$ B pathway is involved in TPAmediated TNFa production.

To assess whether the different sensitivity to SM may be related to a differential ability for the processed $\mathrm{p} 52$ fragment to enter the nucleus, nuclear and cytosolic fractions of TPA or SM-treated MDA-MB-231 and MDA-MB-468 cells were prepared. After $3 \mathrm{~h}$ of LBW242 treatment, p52 as well as the heterodimer Rel B appeared in the nuclear fraction of both cell lines (Figure $6 \mathrm{~d}$ ). Corroborating the results seen in Figure 6b, TPA did not evoke nuclear localization of p52 or Rel B (Figure $6 \mathrm{~d}$ ).

Effects of suppressing non-canonical or canonical NF- $k B$ signaling Both MDA-MB-231 and MDA-MB-468 cell lines respond to SM with p100 processing and nuclear p52 translocation (Figures $6 b$ and d), which indicates activation of the non-canonical NF- $\kappa$ B pathway in both cell lines. However, SM evokes substantial changes in global gene expression including TNFa only in MDA-MB-231 cells (Figures $4 a$ and $b$; Supplementary Table 1). These facts raise the question if non-canonical NF- $\kappa$ B signaling is the actual or sole mediator of TNFa induction. Therefore, we sought to investigate SM-induced TNFa expression when blocking either the non-canonical or the canonical pathway. NIK, an initiator of the non-canonical pathway, was downregulated with three different siRNA oligonucleotides. SM treatment induced NIK accumulation in MDA-MB-231 cells transfected with control siRNA, but this was suppressed in cells transfected with siRNA targeting NIK (Figure 7a). The same was seen for p100 processing to p52, which was essentially abolished in SM-treated cells transfected with NIK siRNA indicating a functional termination of the non-canonical NF- $\kappa B$ pathway. The effects were similar using both the LBW242 and the LCL161 SM (Figure 7a; Supplementary Figure 2a). Similar results were obtained in MDA-MB-468 cells (Figure 7b).

With siNIK as a tool to block the non-canonical NF- $k B$ pathway, we investigated the SM-induced expression of $\mathrm{BIRC} 3$, the most upregulated gene in the microarray analysis, and TNFa (Figure 7c). In siNIK-transfected and SM-treated MDA-MB-231 cells, a decrease in SM-stimulated absolute levels of TNFa and BIRC3 mRNA was observed except for one siRNA in the case of TNFa. However, the fold change in TNFa and BIRC3 mRNA induced by SM was not as influenced by siRNA treatment (Figure 7c). This contrasts MDAMB-468 cells, where downregulation of NIK completely suppressed SM-induced increases in BIRC3 mRNA levels (Figure 7d).

Thus, SM induction of TNFa expression can proceed to some extent in MDA-MB-231 cells even if the non-canonical NF- $\kappa$ B pathway is blocked (Figure 7c). This opens up for a possible role of other pathways. Therefore, we investigated the involvement of the canonical NF- $\kappa$ B pathway using siRNA targeting IKK $\beta$ (Figure 7e). Downregulating IKK $\beta$ with three different siRNAs, all resulted in a strong reduction of TPA-induced TNFa mRNA expression (Figure 7f), indicating a functional suppression of the canonical NF-KB signal. However, downregulation of IKK $\beta$ did not have substantial effects on the SM-induced fold changes 
a
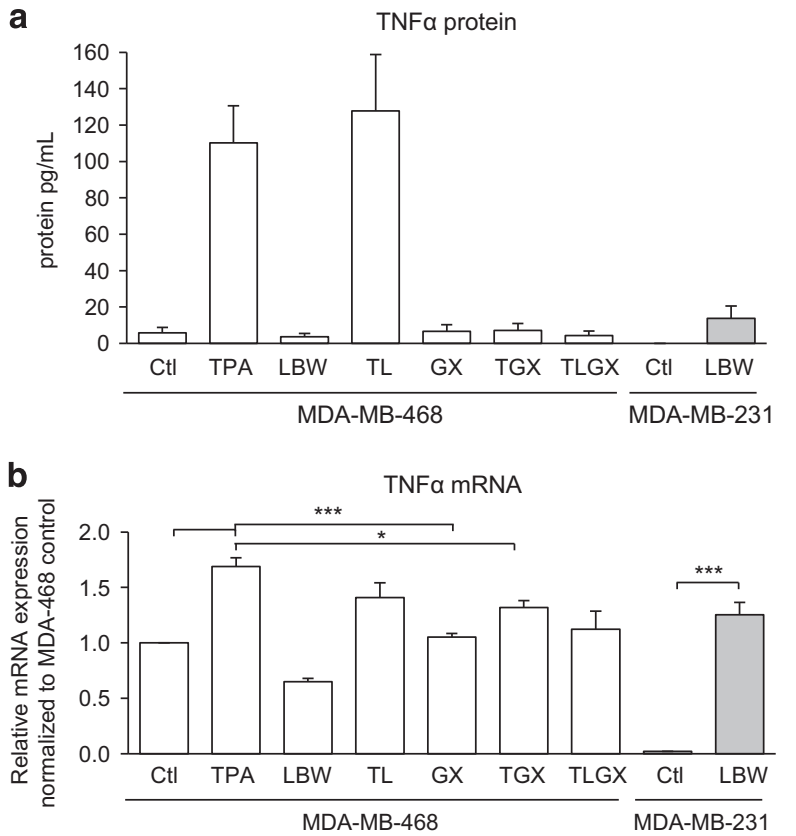

C

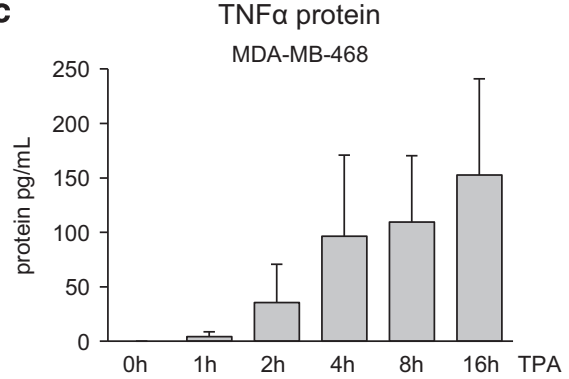

d TNFa mRNA

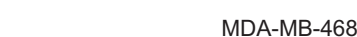

e

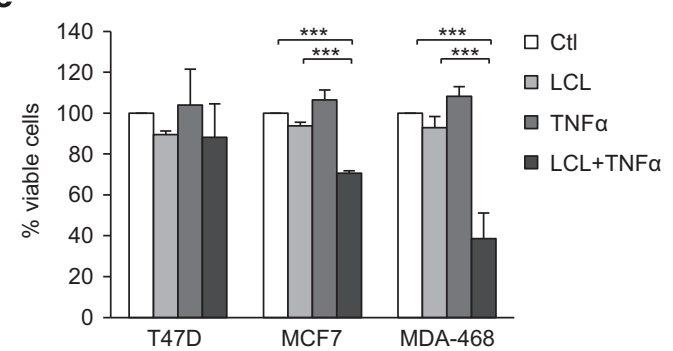

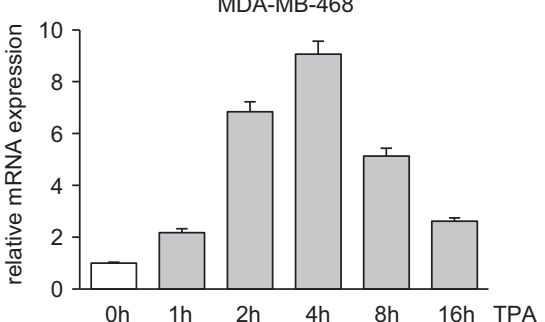

f TNFa mRNA MCF-7 $n=3$

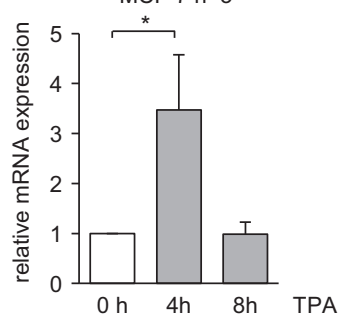

Figure 4. TNFa levels increase upon TPA treatment. (a) MDA-MB-468 and MDA-MB-231 cells were treated for $16 \mathrm{~h}$ with indicated combinations of $16 \mathrm{nM}$ TPA (T), $20 \mu \mathrm{M}$ LBW242 (L) or $2 \mu \mathrm{M}$ GF109203X (GX). The concentration of TNFa protein in the cell culture medium was determined by ELISA. (b) TNFa mRNA levels were determined with qPCR and relative mRNA levels were normalized to control (CtI) MDA-MB-468 cells. (c and d) MDA-MB-468 cells were treated with $16 \mathrm{nM}$ TPA for 0, 1, 2, 4, 8 and $16 \mathrm{~h}$, thereafter levels of TNF $a$ protein in the cell culture medium (c) or mRNA of total cell lysate (d) was determined. (e) T47D, MCF-7 and MDA-MB-468 cells were seeded on a 96-well plate and treated with $2 \mathrm{ng} / \mathrm{ml} \mathrm{TNFa}, 10 \mu \mathrm{M} \mathrm{LCL} 161$ or the combination of both for $30 \mathrm{~h}$. Cell viability data are obtained with a WST-1 assay and are expressed as percentage of control cells. (f) MCF-7 cells were treated with $16 \mathrm{nM}$ TPA for 0,4 or $8 \mathrm{~h}$. Thereafter TNFa mRNA levels were determined with qPCR. All data are mean \pm S.E.M. of $n \geq 3$ independent experiments; ${ }^{*} P<0.05$ and ${ }^{* * *} P<0.001$.

in TNFa or BIRC3 mRNA levels in MDA-MB-231 cells (Figure 7g) although the absolute levels were suppressed in most cases. The pattern was the same for BIRC3 mRNA expression in MDA-MB-468 cells (Figure 7h).

A combined role for the canonical and non-canonical NF- $K B$ pathways

To investigate the possibility of compensatory mechanisms, we inhibited both the canonical and the non-canonical NF-KB pathways with siRNAs targeting NIK and IKK $\beta$. The absolute levels of SM-induced TNFa and BIRC3 mRNA expression in MDA-MB-231 cells were suppressed upon downregulation of each protein alone with an even stronger effect after downregulation of both proteins in combination (Figures 8a-c). However, the SMinduced fold change still persisted following combined knockdown of NIK and IKK $\beta$ even though the absolute TNFa mRNA levels were low, resembling levels of control cells (Figure $8 b$ ). The pattern was the same for BIRC3 (Figure 8c). In line with effects on TNF $a$, the SM-induced cell death was suppressed following treatment with siRNA targeting IKK $\beta$ or NIK (Figure $8 \mathrm{~d}$ ). Combined knockdown of both IKK $\beta$ and NIK resulted in a significant decrease 

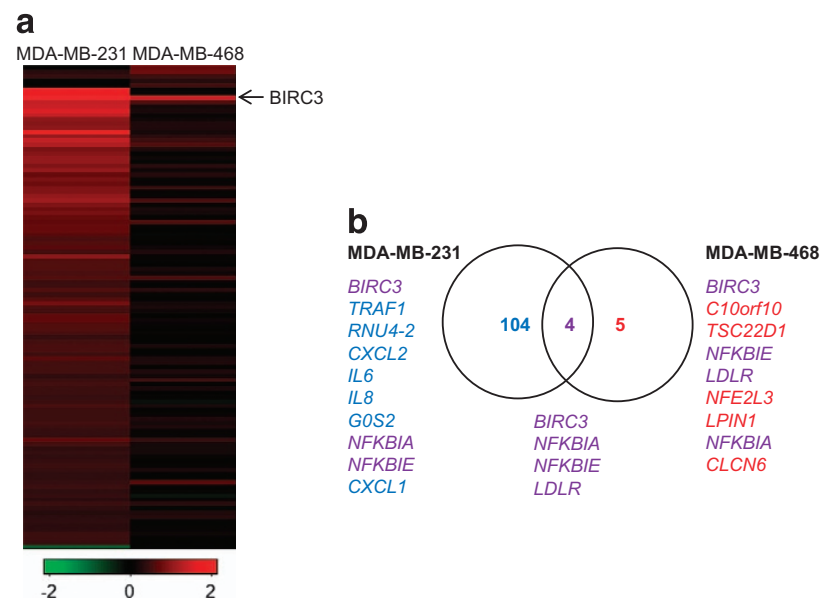

Figure 5. (a) Heatmap visualizing SM-induced fold change in gene expression of genes with a $q$-value of $0 \%$ for MDA-MB-231 (left) and MDA-MB-468 (right). The color code indicates log2 fold change induced by LBW242. (b) Venn diagram displaying the significantly differentially expressed genes, retrieved from the microarray and the subsequent SAM analysis. The genes indicated in the diagram represents all (MDA-MB-468) genes or the top ten (MDA-MB-231) with the highest log2 fold change, in descending order, induced by LBW242 and with a $q$-value $=0 \%$ (Supplementary Table 1), in MDAMB-231 (gene symbol in blue), MDA-MB-468 (gene symbol in red) or in both cell lines (gene symbol in purple).

in cell death whereas knockdown of only one pathway led to a smaller effect. The results indicate that both the canonical and the non-canonical NF-KB pathways contribute to SM-induced TNFa levels and cell death.

\section{DISCUSSION}

Deregulation of cell death is an important contribution to cancer development and may also confer resistance to chemotherapy and radiotherapy. Therefore, promoting cell death induction is one potential strategy for cancer therapy.

One way to promote cell death is by mimicking the function of the pro-apoptotic protein Smac with SM. However, although some cells respond with cell death, most cell types are resistant to SM as single agents. In this report, we show that the PKC activator TPA induces sensitivity to SM in certain basal breast cancer cells and shed light on the differences in SM-induced signaling between sensitive and insensitive cells.

Current understanding indicates that SM-induced cell death involves autocrine TNFa production, ${ }^{16,17}$ although SM-induced cell death independently of TNFa has been reported. ${ }^{13,14,24}$ Our data indicate that TPA promotes sensitivity to SM by initiating the production of TNFa, since TPA induced a de novo production of TNFa with increased TNFa mRNA and protein levels (Figure 4). Furthermore, the TPA effect was blocked by TNF $a$ antibodies, and could be mimicked by addition of TNFa (Figures 3a-d). Thus, induction of local production of TNFa may be one way to render cancer cells sensitive to SM, a notion in line with the report that pathogen mimetics generating a cytokine milieu consisting of IFN $\beta$, TNF $\alpha$ and/or TRAIL sensitizes cancer cells to SM. ${ }^{25}$

The fact that PKC activation can induce TNFa production in many cell lines ${ }^{26-29}$ and the proposed dependency on TNFa for SM-induced death, ${ }^{16,17}$ raise the question why most cell lines were insensitive to the TPA+SM combination (Figure 1a). In fact, only triple-negative breast cancer cell lines were sensitive to this treatment. There are several putative explanations for this, one being that TPA may not lead to sufficiently high TNFa levels in all cell types. One example of this is MCF-7 cells where TPA induces
TNFa expression but with shorter duration and at lower levels than in MDA-MB-468 cells (Figure $4 \mathrm{f}$ ). Another possibility is that the cell does not respond to TNFa. This was the case for T47D cells, which were insensitive to the combination of SM and TNFa (Figure 4e). Insensitivity to the combination of SM and TNFa has also been reported for mesothelioma cells. This was reported to be due to the caspase inhibitory actions exerted by the caspase- 8 inhibitor FLICE-like inhibitory protein (cFLIP). ${ }^{30}$

TNF $a$ is a target gene of the NF- $K B$ signaling pathway ${ }^{31}$ and TPA has been shown to induce NF- $K B$ activation in several cell lines. ${ }^{26,28}$ More recent studies indicate PKC $\delta$ and/or PKC $\varepsilon$ isoforms as mediators of TPA-induced NF- $K B$ activation. ${ }^{27,29}$ Our data show that TPA treatment of MDA-MB-231 and MDA-MB-468 cells results in decreased $I \kappa B a$ levels, indicative of canonical NF- $\kappa B$ signaling (Figure $5 \mathrm{c}$ ), and that downregulation of the canonical pathway (Figure 7f) suppresses the TNFa induction. It is therefore conceivable that de novo synthesis of TNFa, via the canonical NF- $K B$ pathway, is the primary effect of TPA treatment in MDAMB-468 breast cancer cells.

Contrasting the effects of TPA, it has been implied that SM induces TNFa production via the non-canonical NF- $K B$ pathway. ${ }^{16-18}$ This pathway is mediated through activation of NIK. SM treatment can lead to NIK stabilization and activation due to decreased levels of CIAP1 and CIAP2 that ubiquitinate NIK, causing its degradation. ${ }^{16-18}$ Here we show that SM leads to decreased levels of both CIAP1 and CIAP2 in MDA-MB-468 cells (Figure $5 \mathrm{a}$ ) as has previously been described for MDA-MB-231 cells. ${ }^{21}$ The subsequent processing of p100 to p52 was seen for both cell lines (Figure $5 b$ ). Thus, the non-canonical NF- $\kappa$ B signaling pathway is activated by SM in both cell lines but results in TNFa expression only in MDA-MB-231 cells. This may suggest that noncanonical NF- $K B$ signaling is not sufficient for TNFa induction. Our microarray data further indicate that non-canonical signaling does not elicit major changes in gene expression in MDA-MB-468 cells since few genes were upregulated upon SM treatment contrasting the effect in MDA-MB-231 cells. However, both MDA-MB-468 and MDA-MB-231 cell lines showed a substantial increase in BIRC3 expression following $S M$ treatment indicating similar responses to non-canonical NF- $K B$ signaling for this gene.

The fact that the non-canonical pathway is not sufficient for SMmediated TNFa production in MDA-MB-468 raises the question whether other pathways are needed. There is substantial support for a role of NF-KB signaling in SM-induced TNFa expression. ${ }^{32,33}$ Here we used siRNA to inhibit the canonical and the noncanonical NF- $\kappa B$ pathways separately or in combination. Blocking either pathway in the sensitive MDA-MB-231 cell line resulted in lower absolute levels of the NF- $\kappa$ B target genes, TNF $a$ and BIRC3 (Figures $7 \mathrm{c}$ and $\mathrm{g}$ ). However, the ability of SM to induce a relative increase still remained. To suppress SM-stimulated TNFa and BIRC3 levels down to those of untreated control and to mediate a significant decrease in cell death, inhibition of both pathways were required (Figures $8 \mathrm{~b}-\mathrm{d}$ ). However, even when both NF- $K B$ pathways are suppressed there is still a relative increase in TNFa mRNA upon SM treatment suggesting that additional IAPregulated mechanisms may be involved. There are several examples of NF- $\kappa$ B-independent roles for IAPs, such as facilitation of Myc-promoted proliferation by ubiquitinating the Myc-negative regulator Max-dimerization protein-1 (Mad1), ${ }^{34}$ control of cyclin transcription by regulation of E2F $1^{35}$ and the findings that CIAP1 and XIAP affect morphology of cells by acting on Rho GTPases. ${ }^{36,37}$

Other potential mechanisms are suggested in studies identifying mechanisms of SM resistance, such as in vivo-selected SMresistant MDA-MB-231 sublines where lower levels of the leucinerich repeats and immunoglobulin-like domains 1 (LRIG1) were found. LRIG1 depletion also attenuated production of and influenced the sensitivity to TNFa. ${ }^{38}$ Furthermore, the interferon regulatory factor 1 (IRF1) was shown to be important for SMmediated TNFa induction and SM sensitivity. ${ }^{39}$ Another report 


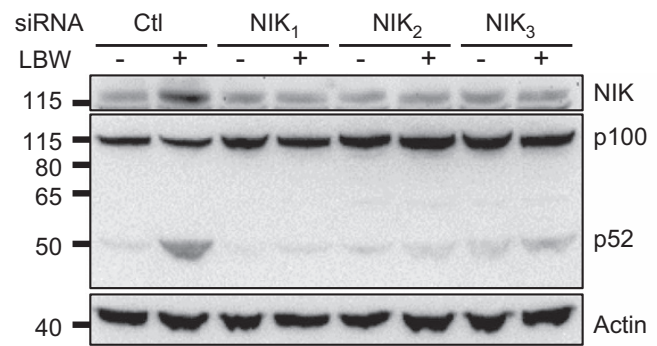

b

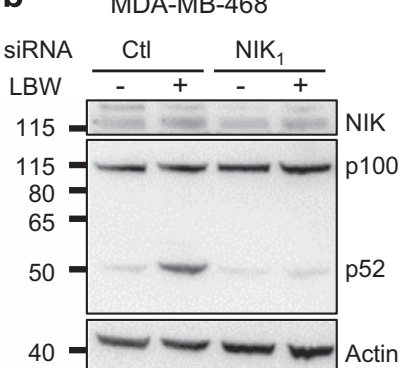

C

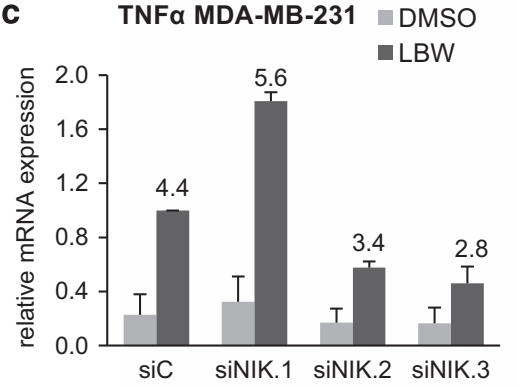

BIRC3 MDA-MB-231 DMSO

- LBW

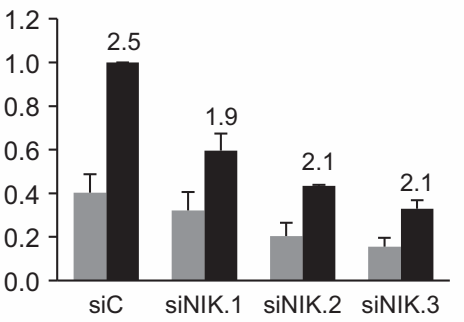

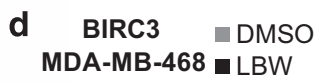

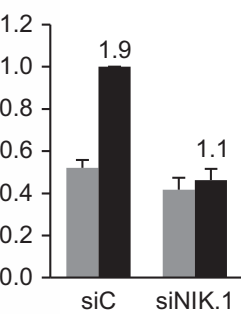

e
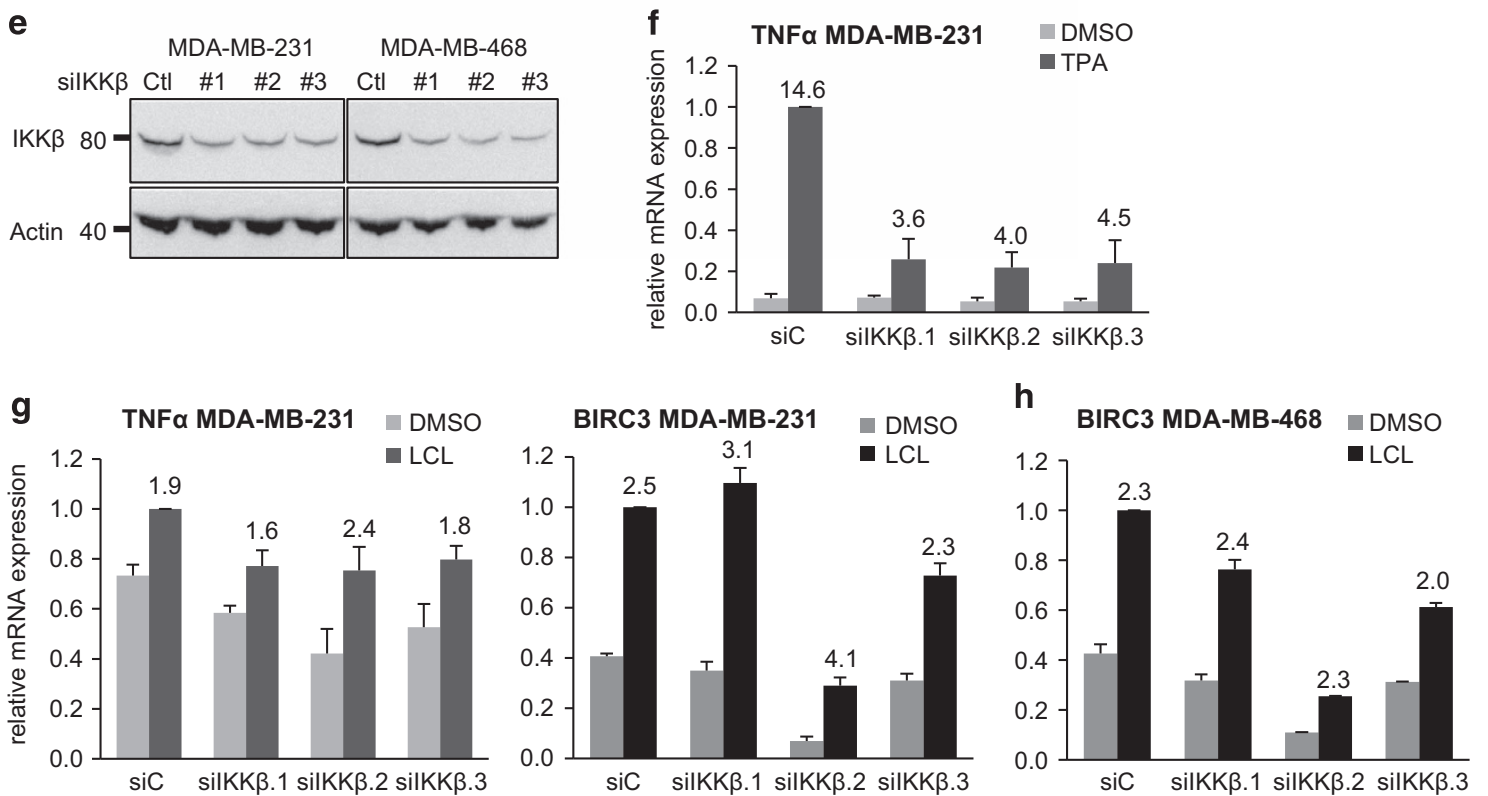

Figure 7. Individual suppression of non-canonical and canonical NF- $K B$ signaling. (a) MDA-MB-231 cells were transfected with three different siRNA oligos (b) and MDA-MB-468 were transfected with one of the siRNA oligos targeting NIK. Both cell lines were treated with $20 \mu \mathrm{M}$ LBW242 for $3 \mathrm{~h}$. NIK expression and processing of p100 to p52 was evaluated by western blot, one representative blot out of three independent experiments is shown. Actin is used as a loading control. (c and $\mathbf{d}$ ) The mRNA levels of TNFa and BIRC3 were determined by qPCR. (e) MDA-MB-231 and MDA-MB-468 cells were transfected with three different siRNA oligos targeting IKK $\beta$, protein expression was evaluated with western blot. (f) Transfected MDA-MB-231 cells were treated with $16 \mathrm{nM}$ TPA for $3 \mathrm{~h}$ and TNFa mRNA levels were analyzed with qPCR. ( $\mathbf{g}$ and $\mathbf{h}$ ) Transfected cells were treated with $10 \mu \mathrm{M}$ LCL161 for $3 \mathrm{~h}$. TNF $a$ and BIRC3 mRNA levels were evaluated with qPCR. The numbers above each bar indicate the fold change in mRNA levels between treated and untreated samples for each siRNA. All qPCR results are mean \pm S.E.M. of $n=3$ independent experiments.

$30 \mathrm{~h}$ of which the last $4 \mathrm{~h}$ were in combination with $10 \mu \mathrm{l}$ WST-1 (Roche, Penzberg, Germany). The amount of viable cells was thereafter assessed by measuring the conversion of WST-1 to a water-soluble formazan dye. Absorbance $(450 \mathrm{~nm})$ was measured by the Synergy 2 Microplate reader (BioTek, Winooski, VT, USA) and analyzed with the Gen5 Reader Control and Data Analysis software (BioTek).

\section{Analysis of complex II formation}

For complex II immunoprecipitations, cells were treated with indicated agents in the presence of $20 \mu \mathrm{M}$ zVADfmk to enable uncleaved caspase- 8 immunoprecipitation as previously described. ${ }^{21}$ Cells were washed once and collected in ice-cold PBS and centrifuged before adding $500 \mu \mathrm{l}$ kit lysis buffer (Miltenyi Biotec, Bergisch Gladbach, Germany) containing $40 \mu \mathrm{l} / \mathrm{ml}$ complete protease inhibitors (Roche Applied Science, Penzberg, Germany). Lysates were cleared by centrifugation at $14000 \times g$ for $10 \mathrm{~min}$. Immunoprecipitations were performed using caspase-8 antibodies $(1: 75$, Cell Signaling 9746, Danvers, MA, USA) together with $\mu$ MACS Protein G MicroBeads (Miltenyi Biotec).

Immunoprecipitates were added to MACS Separation Columns (Miltenyi Biotec), washed in kit buffers and proteins were eluted with heated sample buffer containing the reducing agent dithiothreitol. 
a
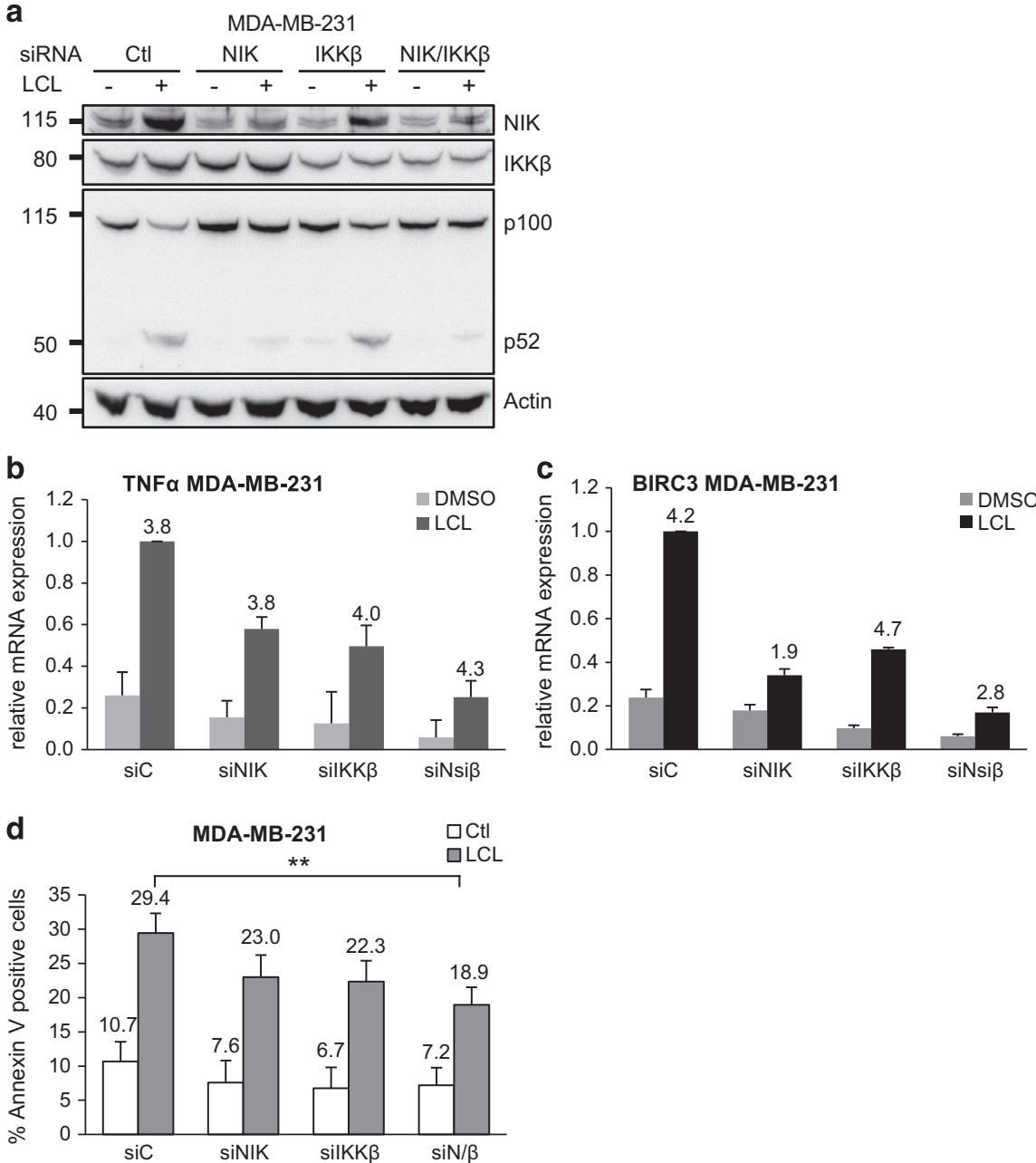

Figure 8. Combined suppression of the canonical and non-canonical NF-KB pathways. MDA-MB-231 cells were transfected with siRNA oligos targeting NIK, IKK $\beta$ or the combination of both for $48 \mathrm{~h}$ and treated with $10 \mu \mathrm{M} \mathrm{LCL} 161$ for $3 \mathrm{~h}$. (a) NIK, IKK $\beta$, p100 and p52 protein expression was evaluated with western blot, and actin was used as a loading control. (b, c) TNFa and BIRC3 mRNA levels were analyzed with qPCR. The numbers above each bar indicate the fold change of mRNA levels between treated and untreated sample for each siRNA. (d) Cell death was determined by flow cytometry using APC-conjugated annexin V. All results represent the mean \pm S.E.M. of $n=4$ independent experiments; $* * P<0.01$.

\section{Western blot}

Cells were washed in ice-cold PBS and lysed in RIPA buffer (10 mM Tris-HCl $(\mathrm{pH}$ 7.2), $160 \mathrm{mM} \mathrm{NaCl}, 1 \%$ Triton X-100 (Sigma-Aldrich), 1\% sodium deoxycholate, $0.1 \%$ sodium dodecyl sulfate, $1 \mathrm{mM}$ EDTA and $1 \mathrm{mM}$ EGTA) containing $40 \mu \mathrm{l} / \mathrm{ml}$ complete protease inhibitors (Roche Applied Science). Lysates were cleared by centrifugation at $14000 \times g$ for $10 \mathrm{~min}$. Equal amounts of proteins were electrophoretically separated on $10 \%$ NuPAGE Novex Bis-Tris gels (Life Technologies-Invitrogen) and transferred to polyvinylidene difluoride membranes (Millipore, Billerica, MA, USA). Membranes were blocked with $5 \%$ non-fat milk in PBS, and probed with antibodies toward actin $(1: 2000$, MP Biomedicals 691001, Santa Ana, CA, USA and 1:1000 sc-81178), caspase-3 (1:500, Pharmingen 67341A), caspase-8 (1:500, Cell Signaling 97465), cIAP1 $(1: 200$, R\&D AF8181, Minneapolis, MN, USA), CIAP2 ( $1: 300$ NB110-57030), p52/p100 (1: 300, Cell Signaling \#4882), Rel B (1:300 sc-48366), p65 (1:400 sc-372), $a$-tubulin (1: 400 sc-5286), lamin B (1:400 sc-6216) and RIP1 (1:300 BD Trans Lab 610458 , Franklin Lakes, NJ, USA), followed by incubation with a horseradish peroxidase-labeled secondary antibody $(1: 5000$ GE Healthcare, Little Chalfont, UK). The chemiluminescence was detected with a chargecoupled device camera (Fujifilm, Minato, Japan).

Analysis of TNFa mRNA levels

Total RNA was extracted with the RNeasy kit (Qiagen, Hilden, Germany) and potential DNA contamination was eliminated with the RQ1 RNase-free DNase (Promega, Madison, WI, USA). In total, $2 \mu \mathrm{g}$ of RNA was used for
cDNA synthesis with MultiScribe Reverse Transcriptase (Applied Biosystems, Foster City, CA, USA). The CDNA was thereafter amplified by qPCR for evaluation of relative mRNA expression levels in an Applied Biosystems 7300 real-time quantitative PCR system using the SYBR Green PCR Master Mix (Applied Biosystems). All primer pairs were from Invitrogen Life Sciences (Waltham, MA, USA), designed with the Primer Express software (Applied Biosystems; forward TNF: 5'-GCAGGTCTACTTTGGGATCATTG-3', reverse TNF: $5^{\prime}$-GCGTTTGGGAAGGTTGGA-3'). The mRNA expression data were normalized to three reference genes (SDHA, UBC and YWHAZ) as described before. ${ }^{41}$ For relative quantification of gene expression, the comparative $\mathrm{Ct}$ method was applied. ${ }^{42}$

Enzyme-linked immunosorbent assay (ELISA)

TNFa protein levels in the cell culture media were determined using the human TNF alpha ELISA kit (Thermo Scientific) according to the manufacturer's protocol. Sample diluent was added to an anti-human TNFa precoated 96 -well strip plate along with cell culture media, from cells with indicated treatment, or with standard and incubated for $1 \mathrm{~h}$. After rinsing the plate with washing buffer, biotinylated antibodies were added, incubated for $1 \mathrm{~h}$ and washed. Streptavidin-HRP reagent was added for $30 \mathrm{~min}$, whereafter the plate was washed before incubation with TMB substrate solution for $30 \mathrm{~min}$ in the dark. Following addition of stop solution, absorbance (at 450 and $550 \mathrm{~nm}$ ) was measured in a Synergy 2 Microplate reader (BioTeck) and analyzed with the Gen5 Reader Control and Data Analysis software (BioTek). 
Nuclear fractionation

Cell fractionation protocol was adapted after Kasperczyk et al. ${ }^{43}$ Briefly, the collected and pelleted cells on ice were resuspended in a low-salt buffer (10 mM HEPES-OH ( $\mathrm{pH} 7.9$ ), $1.5 \mathrm{mM} \mathrm{MgCl} 2$ and $10 \mathrm{mM} \mathrm{KCl}$ ) and incubated at $4{ }^{\circ} \mathrm{C}$ for $10 \mathrm{~min}$. Thereafter, NP-40 with a final concentration of $1 \%$ was added and the sample was vigorously mixed before centrifugation at $1000 \times g$ for $5 \mathrm{~min}$ at $4{ }^{\circ} \mathrm{C}$. The supernatant was centrifuged at $12500 \times g$ for $10 \mathrm{~min}$ at $4^{\circ} \mathrm{C}$ and the resulting supernatant was collected as the cytosol fraction. To retrieve the nuclear fraction, the first pellet was dissolved in a high-salt buffer (20 mM HEPES-OH (pH 7.9), $420 \mathrm{mM} \mathrm{NaCl}$, $1.5 \mathrm{mM} \mathrm{MgCl}, 0.2 \mathrm{mM}$ EDTA and $25 \%$ glycerol) incubated for $15 \mathrm{~min}$ at $4{ }^{\circ} \mathrm{C}$ during which time the pellet was vortexed periodically before centrifugation at $12500 \times \mathrm{g}$ for $10 \mathrm{~min}$ at $4{ }^{\circ} \mathrm{C}$. The resulting supernatant was collected as the nuclear fraction. Both low- and high-salt buffers were supplemented with a protease- and phosphatase inhibitor cocktail: $40 \mu \mathrm{l} / \mathrm{ml}$ complete protease inhibitors (Roche Applied Science), $1 \mathrm{mM}$ sodium-orthovanadate $\left(\mathrm{Na}_{3} \mathrm{VO}_{4}\right)$ and $50 \mathrm{mM} \beta$-glycerophosphate (both from Sigma-Aldrich) before use.

\section{Microarray analysis}

RNA was extracted from MDA-MB-231 and MDA-MB-468 cells after $4 \mathrm{~h}$ of treatment with LBW242 or DMSO using the RNeasy mini kit (Qiagen). Total gene expression analysis was performed by the SCIBLU facility in Lund using the DirectHyb HumanHT-12 v4.0 chip (Illumina, San Diego, CA, USA). Results were normalized using quantile normalization. The significance analysis of microarrays $(\mathrm{SAM})^{44}$ analysis was performed to identify significantly differentially expressed genes in LBW242-treated cells versus control cells. Pathway analysis was performed using the MetaCore webbased program (MetaCore pathway analysis software) by SCIBLU.

\section{Statistical analysis}

Statistical analyses were performed using IBM SPSS Statistics 22 and oneway ANOVA followed by Duncan's multiple range test.

\section{ABBREVIATIONS}

PKC, protein kinase $c_{i}$ Smac, second mitochondria-derived activator of caspases; IAP, inhibitor of apoptosis protein; TPA, 12-O-tetradecanoylphorbol-13-acetate; TNFa, tumor necrosis factor alpha; RIP1, receptorinteracting protein kinase-1; NF- $K B$, nuclear factor kappa-light-chain enhancer of activated B cells; BIRC3, baculoviral IAP repeat-containing 3; DR, death receptor; SM, Smac mimetic; CIAP, cellular IAP; TNFR1, tumor necrosis factor receptor-1; FADD, fas-associated protein with death domain; XIAP, X-linked IAP; NIK, NF-KB-inducing kinase; IKK $\beta$, I-kappa-B kinase- $\beta$; IFN $\beta$, interferon beta; TRAIL, TNF-related apoptosisinducing ligand; $C F L I P$, cellular FLICE-like inhibitory protein; IKB $a$, inhibitor of kappa B alpha; Mad, max-dimerization protein-1; E2F1, E2 promoterbinding factor-1; LRIG1, leucine-rich repeats and immunoglobulin-like domain-1; IRF1, interferon regulatory factor-1; USP11, ubiquitin specific peptidase 11.

\section{ACKNOWLEDGEMENTS}

The authors thank Novartis for generously providing us with the low-molecularweight SM LBW242 and LCL161. The authors acknowledge the help with the microarray analysis from SCIBLU, Microarray Resource Centre at Lund University and the Wallenberg Stiftelse (KAW), with professional assistance from Srinivas Veerla. Financial support was obtained from the Swedish Research Council, the Swedish Cancer Society and the Gunnar Nilsson foundations.

\section{COMPETING INTERESTS}

The authors declare no conflict of interest.

\section{REFERENCES}

1 Hanahan D, Weinberg RA. The hallmarks of cancer. Cell 2000; 100: 57-70.

2 Hanahan D, Weinberg RA. Hallmarks of cancer: the next generation. Cell 2011; 144: 646-674.

3 Galluzzi L, Vitale I, Abrams JM, Alnemri ES, Baehrecke EH, Blagosklonny MV et al. Molecular definitions of cell death subroutines: recommendations of the Nomenclature Committee on Cell Death 2012. Cell Death Differ 2012; 19: 107-120.
4 Galluzzi L, Bravo-San Pedro JM, Kroemer G. Organelle-specific initiation of cell death. Nat Cell Biol 2014; 16: 728-736.

5 Fulda S, Debatin KM. Extrinsic versus intrinsic apoptosis pathways in anticancer chemotherapy. Oncogene 2006; 25: 4798-4811.

6 Schutze S, Tchikov V, Schneider-Brachert W. Regulation of TNFR1 and CD95 signalling by receptor compartmentalization. Nat Rev Mol Cell Biol 2008; 9: 655-662.

7 Tait SW, Green DR. Mitochondria and cell death: outer membrane permeabilization and beyond. Nat Rev Mol Cell Biol 2010; 11: 621-632.

8 Fulda S, Vucic D. Targeting IAP proteins for therapeutic intervention in cancer. Nat Rev Drug Discov 2012; 11: 109-124.

9 Mahoney DJ, Cheung HH, Mrad RL, Plenchette S, Simard C, Enwere E et al. Both CIAP1 and CIAP2 regulate TNFalpha-mediated NF-kappaB activation. Proc Natl Acad Sci USA 2008; 105: 11778-11783.

10 Karin M. Nuclear factor-kappaB in cancer development and progression. Nature 2006; 441: 431-436.

11 Micheau O, Tschopp J. Induction of TNF receptor I-mediated apoptosis via two sequential signaling complexes. Cell 2003; 114: 181-190.

12 Declercq W, Vanden Berghe T, Vandenabeele P. RIP kinases at the crossroads of cell death and survival. Cell 2009; 138: 229-232.

13 Eschenburg G, Eggert A, Schramm A, Lode HN, Hundsdoerfer P. Smac mimetic LBW242 sensitizes XIAP-overexpressing neuroblastoma cells for TNF-alphaindependent apoptosis. Cancer Res 2012; 72: 2645-2656.

14 Allensworth JL, Sauer SJ, Lyerly HK, Morse MA, Devi GR. Smac mimetic Birinapant induces apoptosis and enhances TRAIL potency in inflammatory breast cancer cells in an IAP-dependent and TNF-alpha-independent mechanism. Breast Cancer Res Treat 2013; 137: 359-371.

15 Petersen SL, Wang L, Yalcin-Chin A, Li L, Peyton M, Minna J et al. Autocrine TNFalpha signaling renders human cancer cells susceptible to Smac-mimeticinduced apoptosis. Cancer Cell 2007; 12: 445-456.

16 Varfolomeev E, Blankenship JW, Wayson SM, Fedorova AV, Kayagaki N, Garg P et al. IAP antagonists induce autoubiquitination of c-IAPs, NF-kappaB activation, and TNFalpha-dependent apoptosis. Cell 2007; 131: 669-681.

17 Vince JE, Wong WW, Khan N, Feltham R, Chau D, Ahmed AU et al. IAP antagonists target ClAP1 to induce TNFalpha-dependent apoptosis. Cell 2007; 131: 682-693.

18 Zarnegar BJ, Wang Y, Mahoney DJ, Dempsey PW, Cheung HH, He J et al. Noncanonical NF-kappaB activation requires coordinated assembly of a regulatory complex of the adaptors CIAP1, CIAP2, TRAF2 and TRAF3 and the kinase NIK. Nat Immunol 2008; 9: 1371-1378.

19 Vallabhapurapu S, Matsuzawa A, Zhang W, Tseng PH, Keats JJ, Wang $\mathrm{H}$ et al. Nonredundant and complementary functions of TRAF2 and TRAF3 in a ubiquitination cascade that activates NIK-dependent alternative NF-kappaB signaling. Nat Immunol 2008; 9: 1364-1370.

20 Masoumi KC, Cornmark L, Lonne GK, Hellman U, Larsson C. Identification of a novel protein kinase Cdelta-Smac complex that dissociates during paclitaxelinduced cell death. FEBS Lett 2012; 586: 1166-1172.

21 Tenev T, Bianchi K, Darding M, Broemer M, Langlais C, Wallberg F et al. The Ripoptosome, a signaling platform that assembles in response to genotoxic stress and loss of IAPs. Mol Cell 2011; 43: 432-448.

22 Young $\mathrm{CY}$, Murtha PE, Zhang J. Tumor-promoting phorbol ester-induced cell death and gene expression in a human prostate adenocarcinoma cell line. Oncol Res 1994; 6: 203-210.

23 Hernandez-Vargas H, Rodriguez-Pinilla SM, Julian-Tendero M, Sanchez-Rovira P, Cuevas C, Anton A et al. Gene expression profiling of breast cancer cells in response to gemcitabine: NF-kappaB pathway activation as a potential mechanism of resistance. Breast Cancer Res Treat 2007; 102: 157-172.

24 Greer RM, Peyton M, Larsen JE, Girard L, Xie Y, Gazdar AF et al. SMAC mimetic (JP1201) sensitizes non-small cell lung cancers to multiple chemotherapy agents in an IAP-dependent but TNF-alpha-independent manner. Cancer Res 2011; 71: 7640-7648.

25 Beug ST, Tang VA, LaCasse EC, Cheung HH, Beauregard CE, Brun J et al. Smac mimetics and innate immune stimuli synergize to promote tumor death. Nat Biotechnol 2014; 32: 182-190.

26 Baeuerle PA, Baltimore D. Activation of DNA-binding activity in an apparently cytoplasmic precursor of the NF-kappa B transcription factor. Cell 1988; 53: 211-217.

27 Holden NS, Squires PE, Kaur M, Bland R, Jones CE, Newton R. Phorbol esterstimulated NF-kappaB-dependent transcription: roles for isoforms of novel protein kinase C. Cell Signal 2008; 20: 1338-1348.

28 Sen R, Baltimore D. Inducibility of kappa immunoglobulin enhancerbinding protein Nf-kappa B by a posttranslational mechanism. Cell 1986; 47: 921-928.

29 Garg R, Blando J, Perez CJ, Wang H, Benavides FJ, Kazanietz MG. Activation of nuclear factor kappaB (NF-kappaB) in prostate cancer is 
mediated by protein kinase C epsilon (PKCepsilon). J Biol Chem 2012; 287: 37570-37582.

30 Crawford N, Stasik I, Holohan C, Majkut J, McGrath M, Johnston PG et al. SAHA overcomes FLIP-mediated inhibition of SMAC mimetic-induced apoptosis in mesothelioma. Cell Death Dis 2013; 4: e733.

31 Pahl HL. Activators and target genes of Rel/NF-kappaB transcription factors. Oncogene 1999; 18: 6853-6866.

32 Tchoghandjian A, Jennewein C, Eckhardt I, Rajalingam K, Fulda S. Identification of non-canonical NF-kappaB signaling as a critical mediator of Smac mimeticstimulated migration and invasion of glioblastoma cells. Cell Death Dis 2013; 4: e564.

33 Wagner L, Marschall V, Karl S, Cristofanon S, Zobel K, Deshayes K et al. Smac mimetic sensitizes glioblastoma cells to temozolomide-induced apoptosis in a RIP1- and NF-kappaB-dependent manner. Oncogene 2013; 32: 988-997.

$34 \mathrm{Xu} \mathrm{L}$, Zhu J, Hu X, Zhu H, Kim HT, LaBaer J et al. c-IAP1 cooperates with Myc by acting as a ubiquitin ligase for Mad1. Mol Cell 2007; 28: 914-922.

35 Cartier J, Berthelet J, Marivin A, Gemble S, Edmond V, Plenchette S et al. Cellular inhibitor of apoptosis protein-1 (CIAP1) can regulate E2F1 transcription factor-mediated control of cyclin transcription. J Biol Chem 2011; 286: 26406-26417.

36 Oberoi TK, Dogan T, Hocking JC, Scholz RP, Mooz J, Anderson CL et al. IAPs regulate the plasticity of cell migration by directly targeting Rac1 for degradation. EMBO J 2012; 31: 14-28.

37 Marivin A, Berthelet J, Cartier J, Paul C, Gemble S, Morizot A et al. clAP1 regulates TNFmediated cdc42 activation and filopodia formation. Oncogene 2014; 33: 5534-5545.

38 Bai L, McEachern D, Yang CY, Lu J, Sun H, Wang S. LRIG1 modulates cancer cell sensitivity to Smac mimetics by regulating TNFalpha expression and receptor tyrosine kinase signaling. Cancer Res 2012; 72: 1229-1238.
39 Eckhardt I, Weigert A, Fulda S. Identification of IRF1 as critical dual regulator of Smac mimetic-induced apoptosis and inflammatory cytokine response. Cell Death Dis 2014; 5: e1562.

40 Lee EW, Seong D, Seo J, Jeong M, Lee HK, Song J. USP11-dependent selective CIAP2 deubiquitylation and stabilization determine sensitivity to Smac mimetics. Cell Death Differ 2015; 22: 1463-1476.

41 Lofstedt T, Jogi A, Sigvardsson M, Gradin K, Poellinger L, Pahlman S et al. Induction of ID2 expression by hypoxia-inducible factor-1: a role in dedifferentiation of hypoxic neuroblastoma cells. J Biol Chem 2004; 279: 39223-39231.

42 De Preter K, Speleman F, Combaret V, Lunec J, Laureys G, Eussen BH et al. Quantification of MYCN, DDX1, and NAG gene copy number in neuroblastoma using a real-time quantitative PCR assay. Mod Pathol 2002; 15: 159-166.

43 Kasperczyk H, La Ferla-Bruhl K, Westhoff MA, Behrend L, Zwacka RM, Debatin KM et al. Betulinic acid as new activator of NF-kappaB: molecular mechanisms and implications for cancer therapy. Oncogene 2005; 24: 6945-6956.

44 Tusher VG, Tibshirani R, Chu G. Significance analysis of microarrays applied to the ionizing radiation response. Proc Natl Acad Sci USA 2001; 98: 5116-5121.

(c) (i) This work is licensed under a Creative Commons Attribution 4.0 International License. The images or other third party material in this article are included in the article's Creative Commons license, unless indicated otherwise in the credit line; if the material is not included under the Creative Commons license, users will need to obtain permission from the license holder to reproduce the material. To view a copy of this license, visit http://creativecommons.org/licenses/ by/4.0/

Supplementary Information accompanies the paper on the Cell Death Discovery website (http://www.nature.com/cddiscovery) 